ing the comparative patterns of life-history diversity.

Such a framework leaves two major components of the system to be considered: neonatal and juvenile mortality, and the partitioning of available energy into more and smaller or fewer and larger offspring. In accord with empirical evidence ${ }^{9,10}$, Charnov considers juvenile mortality to be determined by density-dependent factors so as to keep the birth and death rate of the population balanced.

Larger-bodied mammals not only have more energy to put into reproduction, they also wean heavier young and so their fecundity in terms of young produced per unit time is lower than for small-bodied species. Why should larger-bodied species wean heavier young? An interesting feature of Charnov's model is that optimal adult body size is independent of weaning size, so offspring that are weaned heavier will spend less time growing as juveniles and, as a consequence, are more likely to survive to breed themselves.

From these assumptions, Charnov shows that the time between weaning and maturity should increase with the +0.25 power of body size, while litter size per unit time, and both adult and juvenile mortality rates, should scale with the -0.25 power of body size, in accord with the evidence. The theory also predicts that the product of age at maturity and the instantaneous adult mortality rate should be about 0.7 . Data collected from 26 mammal species ${ }^{11}$ fit this expectation.

Work on the covariation of life-history traits among mammal species suggests that size is not everything: life-history variables often covary when size effects are held constant by partial correlation? ${ }^{7}$. For example, those species with an early age at maturity for their body size are also the ones with high adult mortality rates for their body size. Charnov's model can account for such pat-

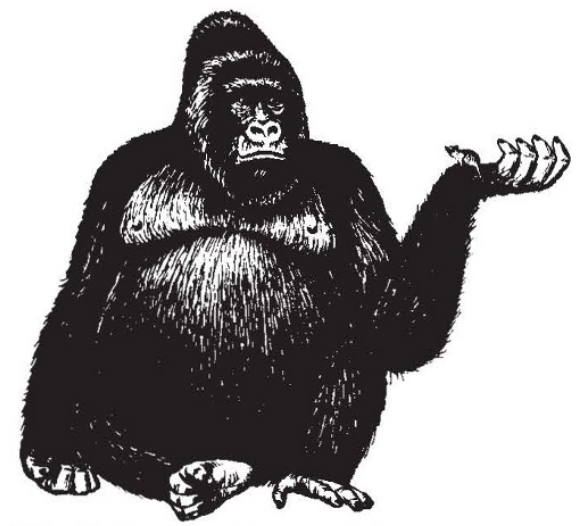

FIG. 2 The smallest and largest primate species, a gorilla Gorilla gorilla and a mouse lemur Microcebus murinus, have very different life-history characteristics.

\section{Safe houses}

THE hovercraft is an elegant device marred by a serious flaw. Its resiliant cushion of compressed air would be an ideal frictionless support, but for the copious and continuous air-flow needed to replenish the steady leakage around the periphery.

So Daedalus is inventing a liquid seal for hovercraft. Modern pumps and compressors are often lubricated with magnetic oil. It contains fine iron or iron-oxide particles which hold it securely in a suitably magnetized bearing even against considerable gas pressure. Daedalus's magnetically sealed hovercraft has a peripheral skirt of flexible, ferrite-loaded magnetized rubber, to which a thick magnetic oil permanently adheres. On a smooth surface, it merely needs to be pumped up until its weight is carried by the air-cushion within. It can then glide frictionlessly along with no further pumping. The oil-seal around the edge cannot be breached by internal pressure, nor wiped away by movement.

At first Daedalus saw this novel craft as an ideal heavy lorry, with no destructive rubber tyres to damage the roads. But he soon realized that it would still have to be propelled, steered and braked by noisy and cumbersome aero-engines. $\mathrm{He}$ is now developing it as a neat and simple support for heavy objects that occasionally must be moved around: cranes, freight containers, portable cabins, even grand pianos and filing cabinets. Fitted with the DREADCO integral hover base, they could be pumped up to neutral buoyancy, manoeuvred effortlessly around, then deflated again to rest firmly in their new location. A vast amount of undignified lifting and shoving, or manipulation with low-loaders and forklift trucks, could be avoided.

Even architecture could benefit. A modern building could be levitated above its concrete-raft foundation with a fraction of an atmosphere of retained air-pressure. Office developers would welcome the chance to shift their monstrosities around, always seeking the currently most fashionable and highest rent locations. But the real benefit would be earthquake protection. For this purpose the magnetized-rubber skirt, as well as being able to slide sideways on its base, would be made deep enough to permit a degree of vertical travel. At the first warning or small preliminary tremor, automatic compressors could pump up the 'hover building' to resilient and frictionless suspension on this private air-cushion. It would then be totally decoupled from lateral or vertical ground-movements which would be fatal to rigidly anchored buildings. When the danger was safely past, the air-cushion would be deflated again, leaving the building erect and stable on its original site, smugly intact amid the ruins of less ingenious structures.

David Jones 